\title{
PENERAPAN TEKNIK KOMBINASI OVERSAMPLING DAN UNDERSAMPLING UNTUK MENGATASI PERMASALAHAN IMBALANCED DATASET
}

\author{
Ariani Indrawati \\ Lembaga Ilmu Pengetahuan Indonesia \\ email: indrawati.ariani@gmail.com
}

(Naskah masuk: 12 Desember 2020, diterima untuk diterbitkan: 4 Februari 2021)

\begin{abstract}
Abstrak
Salah satu permasalahan pada machine learning yang cukup sering terjadi adalah ketidakseimbangan data yang digunakan atau sering disebut dengan imbalanced dataset. Cukup banyak penelitian yang melaporkan bahwa imbalanced dataset ini seringkali memberikan hasil yang keliru. Perlu ada penanganan khusus sebelum imbalanced dataset tersebut dapat digunakan pada machine learning. Cara paling populer dan efektif dalam mengatasi permasalahan imbalanced dataset adalah melakukan resampling, baik oversampling, undersampling, ataupun kombinasi keduanya. Pada penelitian ini akan dilakukan uji coba teknik kombinasi dengan menggabungkan teknik oversampling Synthetic Minority Oversampling Technique (SMOTE) dengan teknik undersampling Edited Nearest Neighbors (ENN) dan TomekLinks terhadap Support Vector Machine (SVM). Tiga public dataset UCI yaitu Breast Cancer Wisconsin, Pima Indian Diabetes, dan Heart Disease Detection digunakan pada penelitian ini dengan Python sebagai alat bantu pemrograman. Berdasarkan hasil uji coba yang dilakukan diketahui bahwa teknik kombinasi dapat membantu mengatasi permasalahan imbalanced dataset pada machine learning, SMOTE-ENN dapat meningkatkan performa akurasi dari SVM sebesar 2\% hingga $23 \%$.
\end{abstract}

Kata kunci: Imbalanced dataset, Resampling, Oversampling, Undersampling

\section{HYBRID OVERSAMPLING AND UNDERSAMPLING TECHNIQUES TO HANDLING IMBALANCED DATASET}

\begin{abstract}
One of the problems in machine learning that often occurs is the imbalance of the data used or often called the imbalanced dataset. Quite a number of studies have reported that imbalanced dataset often gives false results. There needs to be special handling before the imbalanced dataset can be used in machine learning. The most popular and effective way to solve imbalanced dataset problems is resampling, either oversampling, undersampling, or a combination both of them. In this study, we tried a combination technique by combining Synthetic Minority Oversampling Technique (SMOTE) with the Edited Nearest Neighbors (ENN) and TomekLinks undersampling technique against the Support Vector Machine (SVM). We used three public UCI datasets, are Breast Cancer Wisconsin, Pima Indian Diabetes, and Heart Disease Detection in this study, and we also use Python as a programming tools. Based on the results of the experiment, it is known that the combination technique can solve the problem of imbalanced dataset in machine learning, SMOTE-ENN can improve the accuracy performance of the SVM by $2 \%$ to $23 \%$.
\end{abstract}

Keywords: Imbalanced dataset, Resampling, Oversampling, Undersampling

\section{PENDAHULUAN}

Permasalahan imbalanced dataset seringkali kita jumpai pada berbagai domain, dimana jumlah data pada tiap kelas tidak seimbang. Imbalanced data terjadi ketika jumlah data dalam satu kelas jauh lebih tinggi (majority class) atau lebih rendah (minority class) dibandingkan kelas lainnya. Imbalanced data akan lebih sulit untuk dilakukan pengolahan dan analisis data seperti klasifikasi, pengklusteran, prediksi, dan sebagainya. Hal tersebut terjadi karena model analisis data tidak dirancang untuk mempertimbangkan distribusi kelas dalam meningkatkan akurasi dari model. Banyak penelitian yang melaporkan analisis data dengan imbalanced data seringkali memberikan hasil yang keliru.

Perlu ada penanganan khusus sebelum imbalanced data tersebut dapat digunakan untuk proses analisis data. Cara paling populer dalam mengatasi permasalahan imbalanced data adalah melakukan resampling dengan mengubah jumlah data pada tiap 
kelas hingga mencapai jumlah data yang seimbang pada seluruh kelas dan merupakan sebuah teknik yang efektif $[1,2]$.

Banyak metode resampling telah diajukan baik oversampling maupun undersampling. Metode-metode untuk teknik oversampling antara lain, Random Over Sampling (ROS), Synthetic Minority Oversampling Technique (SMOTE) [3], Borderline SMOTE [4], kMeans SMOTE [5], Support Vector Machine SMOTE (SVM-SMOTE) [6], Adaptive Synthetic (ADASYN) [7], dll. Sedangkan untuk undersampling antara lain, Random Under Sampling (RUS), TomekLinks [8], Edited Nearest Neighbors (ENN) [9], One Side Selection (OSS) [10], Neighborhood Cleaning Rule (NCR) [11], dan sebagainya. Metode-metode oversampling atau undersampling tersebut telah diterapkan pada beberapa penelitian [12 - 18]

Namun, teknik oversampling dan undersampling memiliki celah atau kekurangan, oversampling yang dilakukan secara acak dapat mengakibatkan overfitting pada model yang dibentuk [1, 19], sedangkan undersampling dapat menghilangkan bagian-bagian penting pada majority class sehingga batas keputusan antar kelas lebih sulit dipelajari dan berpengaruh terhadap performa klasifikasi [7].

Dalam mengatasi kekurangan tersebut, pada penelitian ini akan dilakukan uji coba teknik kombinasi dengan menggabungkan teknik oversampling SMOTE dengan teknik undersampling ENN (SMOTE-ENN) dan TomekLinks (SMOTE-Tomek) untuk melakukan resampling terhadap 3 dataset UCI yaitu Breast Cancer Wisconsin, Pima Indian Diabetes, dan Heart Disease Detection. Selanjutnya dataset hasil resampling akan dilakukan klasifikasi menggunakan SVM. SVM dipilih karena beberapa penelitian menyatakan bahwa SVM merupakan metode paling baik dibandingkan dengan metode lainnya [20 - 25].

\section{METODE PENELITIAN}

Dalam melakukan resampling data terdapat 2 teknik, yaitu oversampling dengan menambahkan sejumlah data pada minority class, serta undersampling dengan mengurangi jumlah data pada majority class. Ilustrasi oversampling dan undersampling dapat dilihat pada gambar 1 .

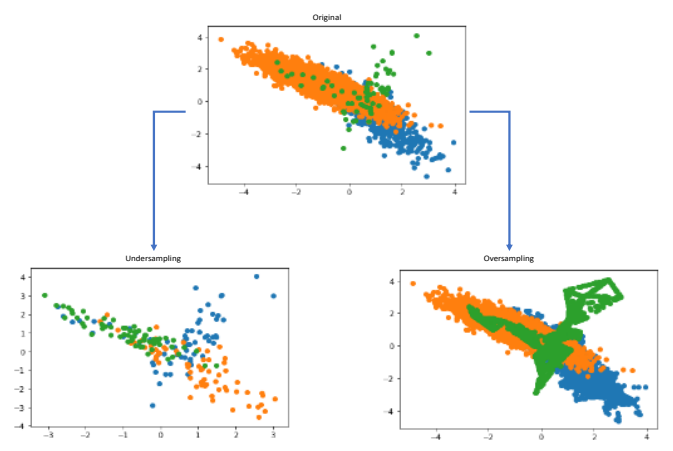

Gambar 1. Ilustrasi oversampling dan undersampling
Pada penelitian ini, langkap pertama adalah tahap pengumpulan imbalanced data yang kemudian akan dibagi $70 \%$ untuk pemodelan atau pelatihan dan $30 \%$ untuk data pengujian. Kemudian, data pelatihan akan dilakukan dilakukan oversampling data menggunakan metode SMOTE dan undersampling menggunakan TomekLinks dan ENN. Data hasil resampling tersebut dilakukan pemodelan klasifikasi menggunakan SVM. Tahap terakhir adalah pengujian precision, recall, dan $f$-measure dari pemodelan yang sudah terbentuk menggunakan data uji. Seluruh tahapan tersebut diproses dengan memanfaat Python sebagai alat bantu. Source code pada penelitian ini dapat diakses pada rin.lipi.go.id setelah artikel ini terbit. Gambar 2 mengilustrasikan tahapan yang akan dilakukan pada penelitian ini.

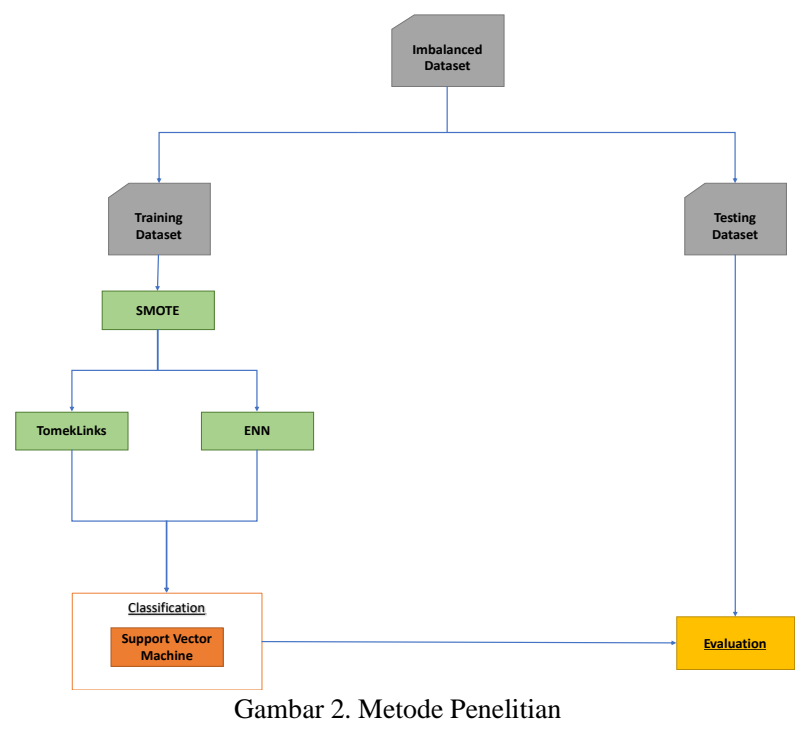

A. Dataset

Penelitian ini menggunakan 3 dataset yang bersumber dari UCI Machine Learning Repository (https://archive.ics.uci.edu/ml/datasets.php).

a. Breast cancer dataset berjumlah 469 data yang dibagi menjadi 2 kelas, Benign dengan 357 data dan Malign dengan 212 data. presentase jumlah data dari minority class dan majority class dapat dilihat gambar 3 .

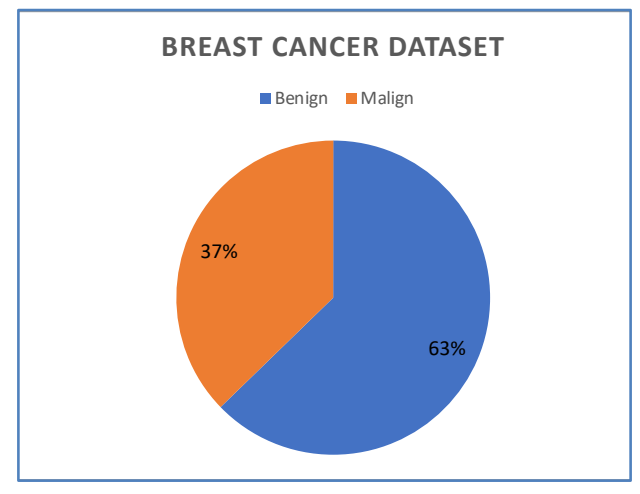

Gambar 3. Distribusi dataset breast cancer 
b. Pima Indian Diabetes dataset berjumlah 768 data yang dibagi menjadi 2 kelas, Diabetic dengan 500 data dan Non-diabetic dengan 268 data. presentase jumlah data dari minority class dan majority class dapat dilihat gambar 4 .

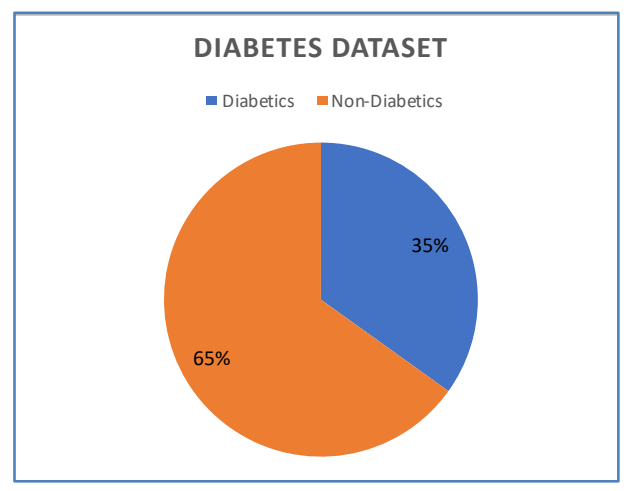

Gambar 4. Distribusi dataset diabetes

c. Breast cancer dataset berjumlah 303 data yang dibagi menjadi 2 kelas, pasien yang menderita penyakit jantung (kelas 1 / Yes) dengan 138 data dan pasien yang tidak menderita penyakit jantung (Kelas 0 / No) dengan 165 data. presentase jumlah data dari minority class dan majority class dapat dilihat gambar 5 .

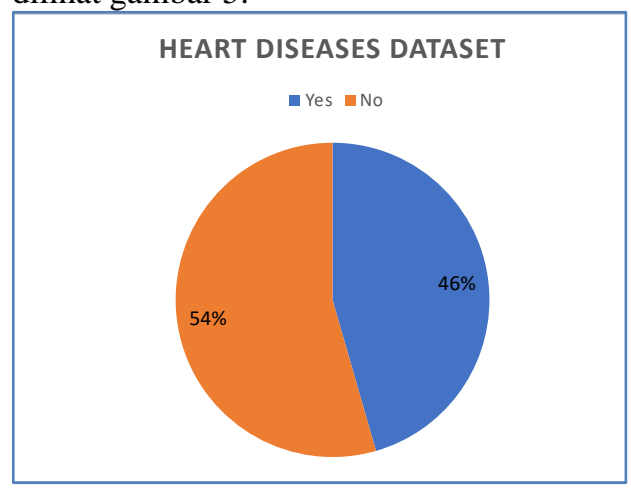

Gambar 5. Distribusi dataset heart disesase

\section{B. Metode Resampling}

Pada penelitian ini akan dilakukan ujicoba pengaruh teknik kombinasi SMOTE-ENN dan SMOTE-Tomek dimana imbalanced data akan dilakukan oversampling akan dilakukan dengan menggunakan SMOTE, kemudian data akan coba dikurangi menggunakan metode undersampling ENN dan TomekLinks. Bagian ini akan menyajikan penjelasan singkat mengenai metode SMOTE, ENN, dan TomekLink yang akan digunakan sebagai kombinasi resampling pada penelitian ini.

\section{a. SMOTE}

SMOTE dikenalkan pertama kali oleh Chawla pada tahun 2002. Cara kerja SMOTE adalah dengan menambahkan data-data buatan pada kelas minority dengan melakukan interpolasi pada data-data asli, sehingga data buatan yang dihasilkan sangat bervariasi. Algoritma dari SMOTE dapat dijelaskan [3]. Ilustrasi hasil oversampling dapat dilihat pada gambar 6, pada original data kelas 0 memiliki 901 data dan kelas 1 hanya memiliki 99 data, setelah dilakukan oversampling menggunakan SMOTE data pada kelas 1 bertambah menjadi 901 data.
Original Data
Counter(\{0: 901, 1: 99\})

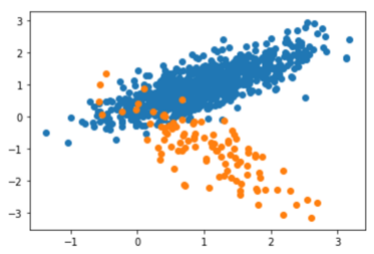

Resampling Data (SMOTE)
Counter(\{0: $901, \quad 1: 901\})$

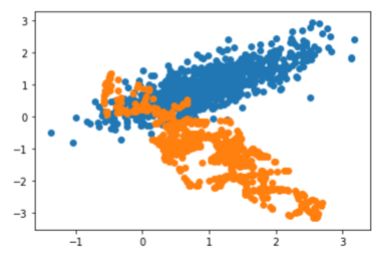

b. ENN

Gambar 6. Ilustrasi SMOTE

Dalam metode ENN yang diajukan oleh Wilson [9], undersampling pada majority class dilakukan dengan cara menghilangkan sampel dari majority class yang memiliki label berbeda pada data-data yang berdekatan. Metode ini sangat bergantung pada nilai $k$ yang dipilih. Hasil undersampling diilustrasikan pada gambar 7, dapat dilihat bahwa data majority class (kelas 1) yang semula berjumlah 901 data berkurang menjadi 602 data.

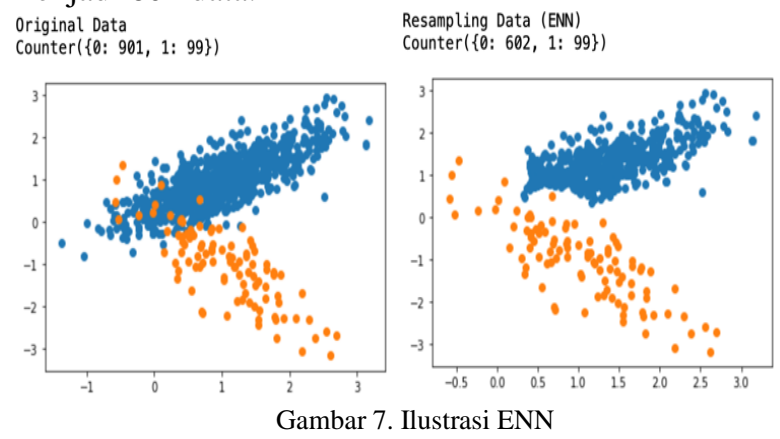

\section{c. TomekLink}

TomekLinks diajukan oleh Tomek pada tahun 1972. Metode ini mengurangi sampel dengan cara 2 data yang saling berdekatan antara minority class dan majority class. Pada gambar 8, original data dan hasil resampling menggunakan TomekLink memang terlihat hampir sama, namun jika dihitung dari jumlah data majority class berkurang menjadi 892 data dari 901 data.

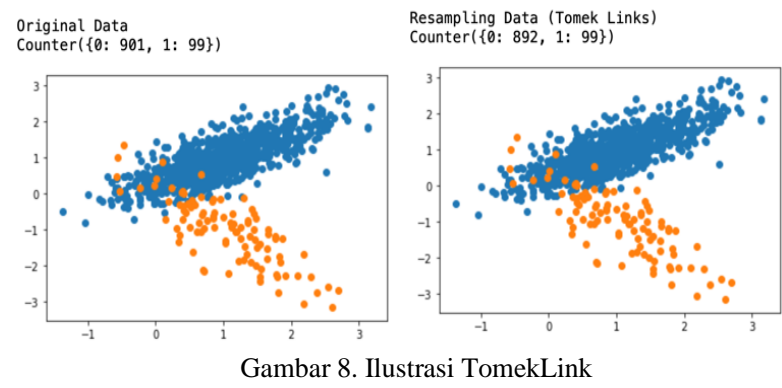




\section{HASIL DAN PEMBAHASAN}

Pada bagian ini akan dijelaskan hasil eksperimen yang dilakukan pada penelitian ini untuk mengetahui pengaruh penerapan 2 metode kombinasi oversampling dan undersampling, yaitu SMOTEENN dan SMOTE-Tomek, terhadap performa metode klasifikasi SVM.

Langkah pertama yang dilakukan adalah melakukan oversampling pada setiap dataset menggunakan SMOTE. Data breast cancer terdapat penambahan data sebanyak 145 pada kelas Malign. Pada data diabetes mengalami penambahan data yang cukup siginifikan sebesar 232 pada kelas Diabetic, sedangkan pada data heart disease bertambah sebanyak 27 data kelas 1 .

Langkah selanjutnya adalah melakukan proses undersampling dengan mengurangi hasil oversampling dengan metode TomekLink dan ENN pada kedua kelas baik majority class maupun minority class. Sebaran data dari proses resampling dapat dilihat pada gambar 9 untuk data breast cancer, gambar 10 untuk data pima Indian diabetes, dan gambar 11 untuk data heart diseases. Distribusi jumlah data pada masing-masing sebelum dan setelah proses resampling dengan teknik kombinasi dapat dilihat pada tabel 1 .

Tabel 1. Jumlah Data Sebelum dan Sesudah Resampling

\begin{tabular}{|c|c|c|c|c|c|}
\hline \multirow[b]{2}{*}{ Dataset } & \multirow[b]{2}{*}{ Kelas } & \multicolumn{4}{|c|}{ Jumlah Data } \\
\hline & & $\begin{array}{c}\text { Origin } \\
\text { al }\end{array}$ & $\begin{array}{c}\text { SMOT } \\
\quad E\end{array}$ & $\begin{array}{l}\text { SMOT } \\
\text { E-ENN }\end{array}$ & $\begin{array}{c}\text { SMOT } \\
\text { E- } \\
\text { Tomek }\end{array}$ \\
\hline \multirow{2}{*}{$\begin{array}{l}\text { Breast } \\
\text { Cancer }\end{array}$} & Benign & 357 & 357 & 318 & 348 \\
\hline & Malign & 212 & 357 & 303 & 348 \\
\hline \multirow{2}{*}{$\begin{array}{l}\text { Diabete } \\
\quad s\end{array}$} & $\begin{array}{c}\text { Diabetic } \\
s\end{array}$ & 268 & 500 & 296 & 471 \\
\hline & $\begin{array}{c}\text { Non- } \\
\text { Diabetic } \\
s\end{array}$ & 500 & 500 & 225 & 471 \\
\hline \multirow{2}{*}{$\begin{array}{c}\text { Heart } \\
\text { Disease }\end{array}$} & Yes & 138 & 165 & 49 & 141 \\
\hline & No & 165 & 165 & 44 & 141 \\
\hline
\end{tabular}

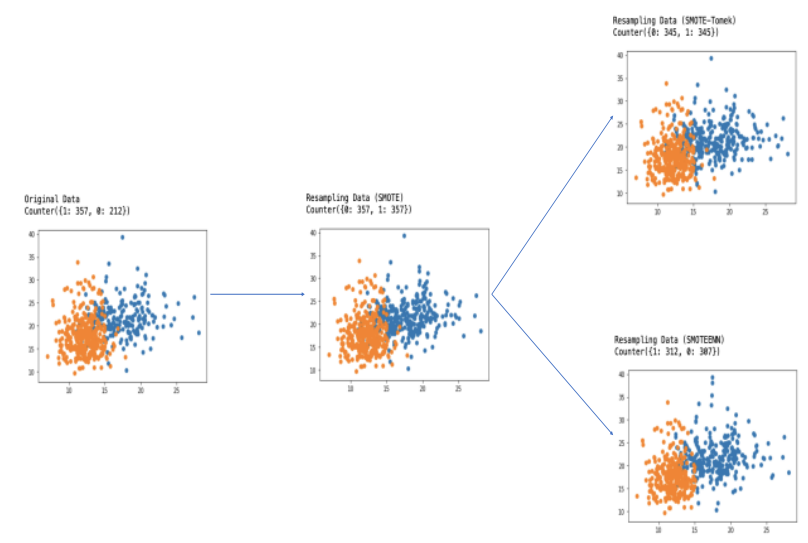

Gambar 9. Sebaran data breast cancer tiap tahap resampling

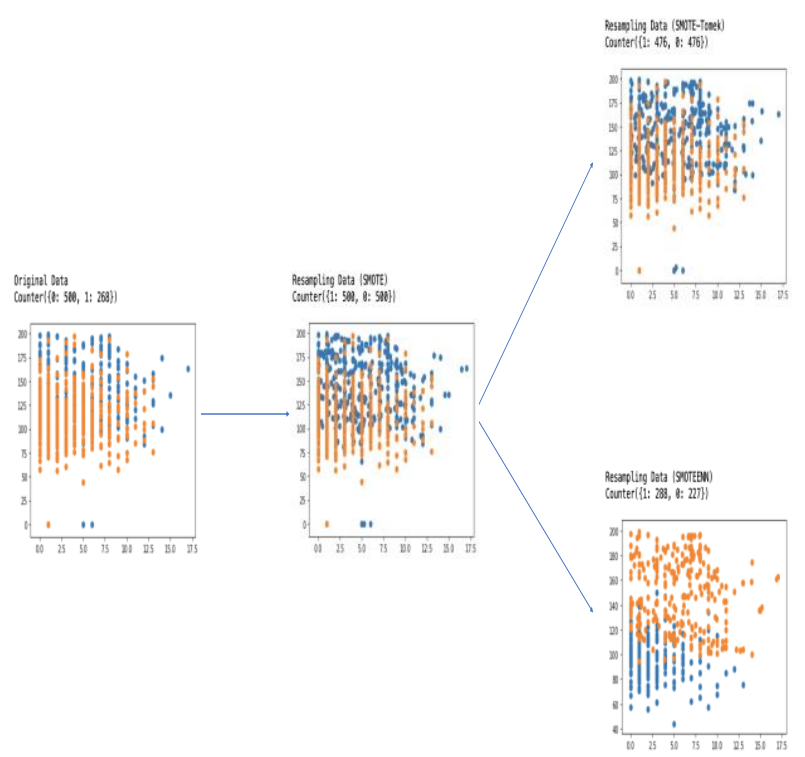

Gambar 10. Sebaran data pima Indian diabetes tiap tahap resampling

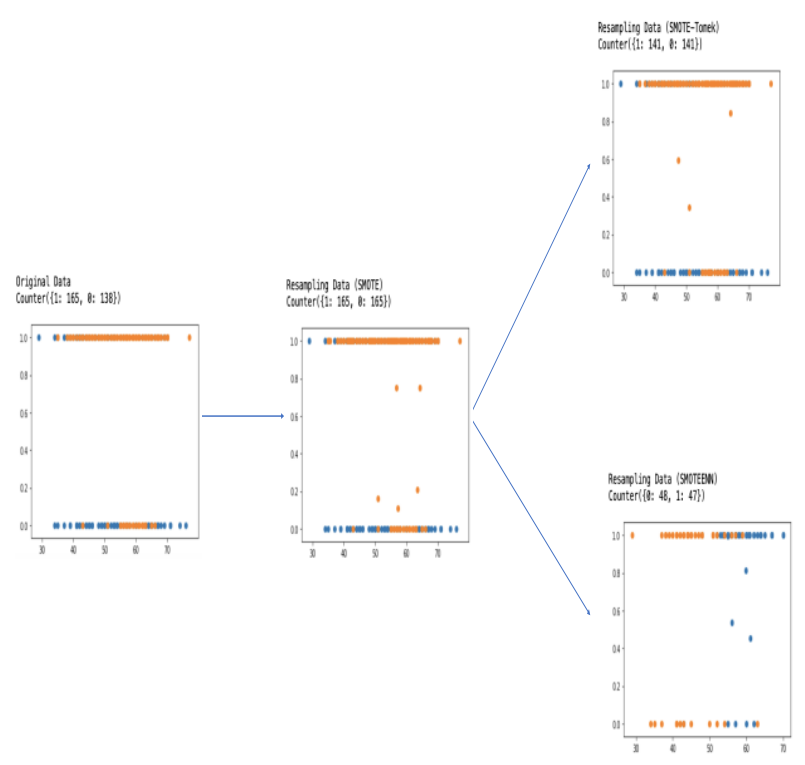

Gambar 11. Sebaran data heart disease tiap tahap resampling

Setelah dilakukan proses resampling, langkah selanjutnya adalah membagi data menjadi data latih dan data uji dengan perbandingan 70:30. Data latih akan digunakan untuk pemodelan SVM, sedangkan data uji akan digunakan untuk menguji precision, recall, $\operatorname{dan} f$ Measure dari model yang dibentuk. Hasil ketiga nilai tersebut dapat dilihat pada gambar 12. Pada breast cancer dataset, resampling menggunakan SMOTEENN mampu menaikan $f$-Measure sebesar 0.02, namun sebaliknya SMOTE-Tomek menurunkan $f$-Measure menjadi dari 0.95 menjadi 0.93. Pada dataset Pima Indian Diabetes, kedua metode resampling dapat meningkatkan $f$-Measure sebesar 0.22 untuk SMOTEENN dan 0.06 untuk SMOTE-Tomek. Pada heart disesases dataset, SMOTE-ENN dan SMOTE-Tomek berhasil meningkatkan $f$-Measure sebesar 0.23 dan 0.11 . 


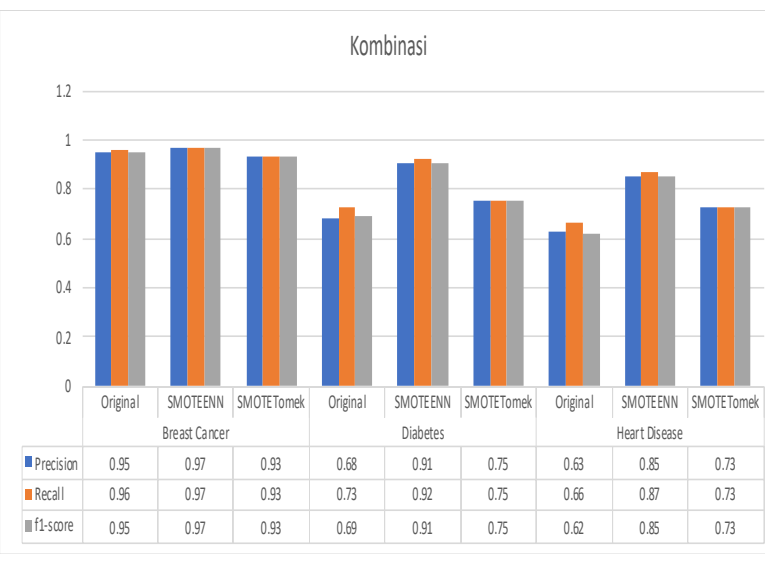

Gambar 12. Precision, Recall, dan f-Measure SMOTE-ENN dan SMOTE-Tomek

\section{KESIMPULAN}

Teknik resampling merupakan cara sederhana yang dapat membantu menangani permasalahan imbalanced dataset pada machine learning, baik oversampling, undersampling, maupun kombinasi keduanya. Hal tersebut dapat dilihat dari kenaikan nilai precision, recall, dan f-Measure pada ketiga dataset yang digunakan. Namun, tidak semua permasalahan imbalanced data dapat diselesaikan dengan teknik ini. Contoh kasus dapat dilihat pada breast cancer dataset dimana proses resampling menggunakan SMOTE-Tomek menurunkan $f$ Measure. Oleh karena itu, teknik ini harus digunakan dengan memperhatikan karakteristik data dan mesin klasifikasi yang digunakan.

\section{DAFTAR PUSTAKA}

[1] P. Branco., L. Torgo., dan R. Ribeiro. 2015. A Survey of Predictive Modelling under Imbalanced Distributions

[2] A. Hardoni., dan D. P. Rini. 2020. Integrasi Pendekatan Level Data Pada Logistic Regression untuk Prediksi Cacat Perangkat Lunak. JIKO (Jurnal Informatika dan Komputer), 3 (2), pp. 101-106. DOI: $10.33387 /$ jiko

[3] Chawla, N., et al. 2002. SMOTE: Synthetic Minority Over-sampling Technique. Journal of Artificial Intelligence Research, 16. Hal. 321-357. doi: 10.1613/jair.953.

[4] H. Han., et al. 2005. Borderline-SMOTE: A New Over-Sampling Method in Imbalanced Data Sets Learning. Advances in Intelligent Computing, Hal. 878-887. doi: 10.1007/11538059_91

[5] F. Last., et al. 2017. Oversampling for Imbalanced Learning Based on K-Means and SMOTE.

[6] C. Zhang., et al. 2018. A Cost-Sensitive Deep Belief Network for Imbalanced Classification.

[7] H. Haibo., et al. 2008. Adasyn: Adaptive synthetic samplingapproach for imbalanced learning. International Joint Conference on Neural Networks, June, 2008. 10.1109/IJCNN.2008.4633969.
[8] I. Tomek. 1976. Two modifications of CNN. Two Modifications of CNN. iIEEE Transactions on Systems, Man, and Cybernetics. Vol. SMC-6, No. 11: 769-772. doi: 10.1109/TSMC.1976.4309452.

[9] D. L. Wilson. 1972. Asymptotic Properties of Nearest Neighbor Rules Using Edited Data. IEEE Transactions on Systems, Man, and Cybernetics. Vol. SMC-2, No. 3: 408-421, doi: 10.1109/TSMC.1972.4309137.

[10] M. Kubat dan S.Matwin. 1997. Addressing the Curse of Imbalanced Training Sets: One-Sided Selection. 14th International Conference on Machine Learning (ICML97) (USA: Tennessee) 179.

[11] J. Laurikkala. 2001. Improving Identification of Difficult Small Classes by Balancing Class Distribution. 8th Conference on AI in Medicine in Europe AIME01 (Portugal: Cascais) 63.

[12] N. Chamida., M. M. Santoni, dan N. Matondang. 2020. Pengaruh Oversampling pada Klasifikasi Hipertensi dengan Algoritma Naïve Bayes, Decision Tree, dan Artificial Neural Network (ANN). RESTI, 4 (4), pp. 635-641. https://doi.org/10.29207/resti.v4i4.2015.

[13] O. Heranova. 2019. Synthetic Minority Oversampling Technique pada Averaged One Dependence Estimators untuk Klasifikasi Credit Scoring. RESTI, 3 (3), pp. 443-335. https://doi.org/10.29207/resti.v3i3.1275.

[14] R. A. Barro., I. D. Sulvianti., dan F. M. Afendi,. 2013. Penerapan Synthetic Minority Oversampling Technique (SMOTE) terhadap Data Tidak Seimbang pada Pembuatan Model Komposisi Jamu. Xplore, 1 (1), pp. 1-6. https://doi.org/10.29244/xplore.v1i1.12424

[15] S. Al-Azani dan E. El-Alfy. 2018. Imbalanced Sentiment Polarity Detection Using Emoji-Based Features and Bagging Ensemble. Pp. 1-5. 10.1109/CAIS.2018.8441956.

[16] C. Padurariu dan M. Breaban. 2019. Dealing with Data Imbalance in Text Classification. Procedia Computer Science. $159 . \quad 736-745$. 10.1016/j.procs.2019.09.229.

[17] R. M. Pereira., Y. M. G. Costa dan C. N. Silla Jr. 2020. MLTL: A multi-label approach for the Tomek Link undersampling algorithm. Neurocomputing, 383, pp. 95-105. https://doi.org/10.1016/j.neucom.2019.11.076.

[18] R. M. Pereira. et. al. 2018. Dealing with Imbalanceness in Hierarchical Multi-Label Datasets Using Multi-Label Resampling Techniques. $\quad$ 818-824. 10.1109/ICTAI.2018.00128.

[19] A. Fernández., et al. 2018. Learning from Imbalanced Data Sets. 10.1007/978-3-31998074-4.

[20] E. A. Sari., et al. 2020. Klasifikasi Kabupaten Tertinggal Di Kawasan Timur Indonesia dengan Support Vector Machine. JIKO (Jurnal 
Informatika dan Komputer), 3 (3), pp. 188-195. DOI: 10.33387/jiko.v3i3.2364.

[21] L. Vig. 2014. Comparative Analysis of Different Classifiers for the Wisconsin Breast Cancer Dataset. Open Access Library Journal, 1, 1-7. doi: 10.4236/oalib.1100660.

[22] H. Asri. et al. 2016. Using Machine Learning Algorithms for Breast Cancer Risk Prediction and Diagnosis. Procedia Computer Science. 83. 10641069. 10.1016/j.procs.2016.04.224.

[23] S. Ubaidillah., R. Sallehuddin., dan N. A. Ali, N. 2013. Cancer Detection Using Aritifical Neural Network and Support Vector Machine: A Comparative Study. Jurnal Teknologi. 65. 10.11113/jt.v65.1788.

[24] A. Kabir., S. Basuki dan G. W. Wicaksono. 2019. Analisis sentimen kritik dan saran pelatihan aplikasi teknologi informasi (PATI) menggunakan algoritma support vector machine (SVM). Repositor. 1. 10.22219/repositor.v1i1.11.

[25] P. Sinha., dan P. Sinha. 2015. Comparative Study of Chronic Kidney Disease Prediction using KNN and SVM. International Journal of Engineering Research and. V4. 10.17577/IJERTV4IS120622. 